\title{
Zelia Nuttall e Isabel Ramírez: las distintas formas de practicar y escribir sobre arqueología en el México de inícios del siglo XX
}

Apen Ruiz Martinez ${ }^{* *}$

\begin{abstract}
Resumo
Este artículo examina las experiencias de Zelia Nuttall e Isabel Ramírez Castañeda en la antropología mexicana y su participación en la Escuela Internacional de Etnología y Arqueología Americana (1910-1914). Basándome en investigaciones de archivo analizo las distintas maneras de participar en antropología en un momento de profesionalización. Este artículo ofrece información institucional, biográfica y social que nos permite conocer mejor las experiencias de las mujeres antropólogas pioneras.
\end{abstract}

Palavras-chave: Zelia Nuttall, Isabel Ramírez Castañeda, Historia de la Antropología, Género, Nacionalismo.

\footnotetext{
* Recebido para publicação em junho de 2005, aceito em fevereiro de 2006. [Revisão do espanhol: Martha Ramírez.] Este artículo esta basado en mi tesis de doctorado: Insiders and Outsiders in Mexican Archaeology 1890-1920, University of Texas at Austin, 2003.

** Departament d'Humanitats, Universitat Pompeu Fabra, Barcelona, Espanha. apen.ruiz@upf.edu
}

cadernos pagu (27), julho-dezembro de 2006: pp.99-133. 
Zelia Nuttall e Isabel Ramirez...

Zelia Nuttall and Isabel Ramirez Castañeda:

Two Ways to Practice and Write Archaeology at the Beginning of the $20^{\text {th }}$ Century in Mexico

\begin{abstract}
Drawing upon archival records, this article examines the experiences of Zelia Nuttall and Isabel Ramírez Castañeda in Mexican archaeology, their relation with the International School of American Ethnology and Archaeology (1910-1914), and their distinct ways to participate in archaeology in a particular moment of professionalization. This article offers institutional, social, and biographical information that broadens our understanding of the experiences of pioneer women anthropologists.
\end{abstract}

Key words: Zelia Nuttall, Isabel Ramírez Castañeda, History of Anthropology, Gender, Nationalism. 
Apen Ruiz Martinez

En un volumen recientemente publicado de la revista American Anthropologist (2002) aparecieron varios artículos sobre la historia de la antropología americana. La mayoría de los ejemplos y estudios de caso en este volumen, se enfocan en personas e instituciones para narrar el desarrollo de la disciplina. Figuras como Franz Boas, Murray Butler o Frederic Putnam son señaladas como fundamentales para entender la organización actual de la antropología americana. Curiosamente, y aunque de eso se ha hablado poco, estos antropólogos también participaron en la profesionalización de la arqueología mexicana, específicamente a partir de su vinculación con la Escuela Internacional de Arqueología y Etnología Americana (EIAEA) fundada en la Ciudad de México en 1910. (Godoy, 1977:228-242; Rutsch, 2000:131-162) En este artículo también narro las experiencias de personas para relatar un fragmento de la historia de la antropología. Pero en vez de mirar a México desde los Estados Unidos, tomo México como el punto de partida para hablar de cuestiones más amplias que afectan la práctica de la antropología en general. Así, propongo que México no fue tan solo un campo etnográfico o arqueológico para ser explorado por científicos llegados de Estados Unidos, sino un espacio donde profesionales estadounidenses se aproximaron también con el fin de establecer instituciones científicas en colaboración directa con mexicanos.

La Escuela Internacional tenía un carácter netamente multinacional y una intencionalidad cosmopolita, albergando estudiantes y profesores de diferentes naciones (Francia, Prusia, Estados Unidos, Rusia). Sin embargo el final del siglo XIX y los inícios del XX fueron tanto en México como en Estados Unidos y Europa años de nacionalismos y colonialismo que afectaron la antropología y sin duda el funcionamiento de la Escuela. Aunque la EIAEA duró tan solo cuatro años y podría verse como un intento 
Zelia Nuttall e Isabel Ramirez...

fracasado, varios estudios han señalado la importancia que tuvo como precursora de los estudios indigenistas que se consolidaron en la antropología post-revolucionaria mexicana. (Deacon, 1997; Delpar, 1992; De La Peña, 1996:41-81)

El hilo conductor de este artículo es la historia de dos mujeres que participaron de este momento de interacciones científicas entre Estados Unidos y México: Zelia Nuttall e Isabel Ramírez Castañeda. Ellas fueron las dos únicas mujeres que estuvieron relacionadas con la Escuela Internacional de Arqueología y Etnología Americana. Zelia era una norteamericana que se asentó en México durante la primera década del siglo XX y vivió en la capital de México hasta que murió en 1932. Isabel era mexicana y trabajó de forma muy estrecha con científicos extranjeros en México.

Mi interés por ellas como figuras emblemáticas de este momento es doble. En primer lugar, me mueve un deseo de rellenar de mujeres la historia de la ciencia que tiende a ser masculina. A partir de datos archivísticos podemos reseguir, aunque de forma truncada, las vidas de Isabel y Zelia y de esta manera conocer más sobre un grupo de mujeres pioneras que abrieron camino en la antropología y la arqueología. En segundo lugar, las experiencias de ambas mujeres pueden verse como trayectorias de éxito y de fracaso dentro de la historia de la disciplina y ello nos proporciona una visión más completa, menos unilineal de la antropología. (Corrêa, 2003) Por ejemplo, Zelia Nuttall investigó arduamente para mostrar los logros sociales y científicos de la civilización Azteca, y hoy en día sus propuestas han sido aceptadas y tomadas en serio, pero en su momento la voz científica de Zelia fue cuestionada. Isabel, por su parte, eligió una forma de escribir antropología que en su momento fue criticada como poco científica y ello explicaría su "fracaso" como antropóloga, pero que quizás hoy en día se aceptaría como una manera de escribir ciencia y popularizar la antropología.

Zelia e Isabel participaron de pleno en la antropología pero al mismo tiempo, como mujeres, fueron marginadas y por ello 
Apen Ruiz Martinez

practicaron ciencia a su manera y aunque no fueran claramente conscientes de ello, lo hicieron como mujeres. Para explicar mejor esta ambigua posición, en este artículo interrogo y reflexiono sobre las dimensiones de género de dos aspectos de la práctica científica que estuvieron presentes en las vidas de Zelia Nuttall y de Isabel Ramírez: las cuestiones de "espacio" y de "escritura." Como mujeres, las dos tuvieron que hacerse de un espacio propio en unos momentos en que la producción antropológica empieza a concentrarse en museos y universidades. Al mismo tiempo, la profesionalización supuso buscar una forma de escribir preocupada en la presentación de resultados verdaderos y objetivos de la investigación. Estas cuestiones de espacio y escritura acompañaron las experiencias de Zelia e Isabel como antropólogas.

\section{Zelia Nuttall e Isabel Ramírez}

Frederic Putnam y Franz Boas han sido mencionados varias veces como promotores de mujeres en un momento en que la antropología americana no era receptiva a las mujeres. Entre estas mujeres se cita a Alice Fletcher, Mary Hemenwey, Matilda Cox Stevenson, Sara Yorke Stevenson y Elsie Clews Parsons. (Babcock e Parezo, 1988; Deacon, 1997; Gacs, 1989; Mark, 1988; Parezo, 1993; Visweswaran, 1998:87-123) Las implicaciones de estas mujeres en antropología fueron únicas y no siempre motivadas por los mismos ideales. Algunas de estas mujeres eran filántropas que financiaron exploraciones y fundaron museos, pero que no salieron a hacer trabajo de campo; otras trabajaron en archivos, algunas de ellas eran coleccionistas particulares, y otras hicieron trabajo de campo en el sentido más clásico de la palabra. Aunque Zelia e Isabel formaron parte de esta generación de mujeres, poco se conoce de ellas.

Cuando empecé a escribir sobre estas dos mujeres me encontré con un desequilibrio en la información primaria que hizo que mi labor se tomara propiamente como la de una arqueóloga 
Zelia Nuttall e Isabel Ramirez...

ya que tenía que juntar piezas desordenadas para obtener una mejor visión, aunque fuera parcial, de un período de la arqueología y de la participación de las mujeres en él. Mientras Zelia Nuttall ha dejado un amplio legado de cartas personales y documentos que nos permiten un acceso directo a su voz, lo que sabemos de Isabel Ramírez es siempre a través de las voces de otros, personas que trabajaron con ella. Inspirada por el trabajo de Natalie Z. Davis (1987) he tomado en cuenta como otras personas han explicado historias sobre estas dos mujeres porque estas historias nos dicen mucho sobre las dinámicas de género en la ciencia, y específicamente como la imagen social de la mujer en ese momento condicionó las prácticas arqueológicasantropológicas de las mujeres.

Aunque tengamos una imagen difusa de Zelia Nuttall, contamos con bastantes datos que nos permiten obtener una mejor idea de cómo era ella. Quiero empezar con una descripción novelada de ella que hizo D. H Lawrence en su novela La Serpiente Emplumada. En esta novela, Zelia Nuttall está descrita como Mrs. Norris de la siguiente manera:

la señora Norris tenía la cara ligeramente gris y la nariz afilada (...) era arqueóloga y había estudiado las ruinas aztecas durante tanto tiempo que en su rostro había grabado algo de la roca de lava gris negruzca y algunas de las experiencias de los ídolos aztecas, de nariz afilada, ojos algo prominentes y una expresión de fúnebre burla. Hija solitaria de la cultura, de mente resuelta y densa voluntad, había curioseado toda su vida en tomo a las duras piedras de los restos arqueológicos, pero retenido al mismo tiempo un fuerte sentido de la humanidad y una visión algo humorística y fantástica de sus semejantes. Desde el primer momento, Kate la respetó por su aislamiento y su intrepidez. El mundo se compone de una masa de gente y unos pocos individuos. La señora Norris era uno de esos últimos. Cierto que no había renunciado nunca a su juego 
social, pero estaba desparejada, y ella sola podía poner en jaque a todas las parejas. (Lawrence, 2000:33)

Como cualquier otro carácter de una novela, Mrs. Norris es un personaje fabricado por el autor que, sin embargo, cuenta con ciertos aspectos de realidad. Pero quiero dejar de lado las tropas literarias a partir de las cuales Zelia Nuttall de forma simplificada se romantiza para enfatizar dos características del retrato de D. H. Lawrence que me parecen pertinentes para mi argumento. Por un lado la descripción que se hace de Nuttall como una mujer aislada, "hija solitaria de la cultura," "desparejada," que vivió toda su vida entre las piedras y piezas de antigüedad, pero que aun así retenía un sentido humano, como si eso fuera un atributo excepcional para un investigador. Ciertamente, Zelia siempre trabajó de forma independiente y la mayor parte de su investigación la realizó una vez se había divorciado. Con seguridad en esos momentos una mujer científica, independiente y divorciada provocaba toda suerte de comentarios acerca de su aislamiento $e$ incluso su capacidad de ser un ser humano completo. Por otro lado, se resalta la idea de que Nutall era una mujer que sabía jugar su rol social todo el tiempo, porque ello explica la posición que Zelia tuvo en la Escuela Internacional.

Estas son dos peculiaridades de la arqueóloga que de alguna manera $\mathrm{u}$ otra van apareciendo en su trayectoria de vida. Al mismo tiempo, las descripciones noveladas indican que la imagen social de la mujer científica ha sido construida con cuidado. Nancy Parezo escribe algo semejante al hablar de la antropóloga Ruth Benedict, y como mostraré más adelante coincide con la imagen de Isabel Ramírez que sus colegas elaboraron. Parezo dice que

más que otro personaje en antropología, las discusiones de Benedict y de sus contribuciones, se han enfocado en sus características personales - su timidez, melancolía, sordera, generosidad y distancia. Su personalidad es vista como el fundamento de sus ideas. (Parezo, 1993:15) 
Zelia Nuttall e Isabel Ramirez...

Para estas mujeres pioneras en antropología fue difícil que la valoración de sus aportaciones científicas no estuviera mediada por comentarios acerca de su personalidad, sus características físicas o incluso el tono de su voz.

Isabel Ramírez trabajó en la Escuela Internacional como arqueóloga y como folklorista. Gran parte de lo que conozco sobre ella es a partir de colegas como Alden Mason, George Engerrand, Franz Boas, Alfred Tozzer y Eduard Seler que indirectamente escribieron sobre ella en su correspondencia profesional. Poco sabemos de ella, tan solo que nació en 1879 en Milpa Alta, un pequeño pueblo cerca de la Ciudad de México y murió en 1943 a la edad de 64 años. No sabemos si estuvo casada o si tuvo hijos. Su identidad racial o étnica, o su estatus económico también son desconocidos. Sin embargo, Isabel accedió a estudios superiores, lo cual significa que siendo mujer y en México a principio de siglo $\mathrm{XX}$, provenía de un contexto con cierto confort económico.

Fue una arqueóloga pionera en México. A diferencia de Zelia Nuttall que fue autodidáctica, Isabel se educó en el Museo Nacional de México, la única institución mexicana que ofrecía formación arqueológica antes del establecimiento de la Escuela Internacional. (Bernal, 1992; Vázquez, 1993:36-77) Hay que resaltar que Isabel se benefició de un período de transformación en el sistema educativo mexicano, que especialmente afectó a las mujeres. Isabel era una de las 30 mujeres que estudiaron en la Escuela de Altos Estudios de la Ciudad de México, una institución inspirada en el Teacher's College de la Universidad de Columbia en Nueva York. En esta escuela recibió lecciones de antropología y lingüística de Franz Boas. (Cano, 2000a) Durante las dos primeras décadas del siglo, esta institución experimentó un importante proceso de feminización y la proporción de mujeres aumentó de un $15 \%$ en 1910 a un $78 \%$ en 1924. (Cano, 2000a) Las mujeres que a1canzaban estudios superiores se dirigían a profesiones que no desafiaban su función simbólica como madres-cuidadoras. Como antropólogas o maestras, tenían un rol específico dentro de un 
Apen Ruiz Martinez

proyecto nacionalista civilizador, educando a las poblaciones indígenas. (Cano, 2000b:207-243; Visweswaran, 1994) ${ }^{1}$

La participación de Nuttall en la antropología fue diferente, quizás porque pudo mantener autonomía y trabajar desvinculada de una institución, su participación en antropología está más alejada de un proyecto nacionalista como educadora o civilizadora que cumplieron otras mujeres. Zelia tuvo la habilidad o la suerte de poder moverse y hablar a través de distintos contextos nacionales, además su capacidad de relacionarse en esferas de la alta sociedad (tanto política como intelectual) la convirtieron en una figura primordial para la arqueología americana de principios de siglo XX, con claros intereses para establecerse en México. En este sentido, Zelia fue una mediadora entre tradiciones intelectuales y en cierta manera una científica transnacional.

\section{Mediadora entre naciones}

Tal como describía D. H. Lawerence es su novela, la imagen de Zelia como una mujer con claras aptitudes para las relaciones públicas nos ayuda a entender por que Franz Boas, Frederic Putnam y Murray Butler la vieron como una posible negociadora entre mexicanos y norteamericanos en sus planes para establecer la Escuela Internacional en México. Cuando en 1909 Franz Boas y Murray Butler, presidente de la Universidad de Columbia, formalizaron los planes para la organización de la EIAEA, Zelia estaba ya residiendo en una casa en el barrio de Coyoacan en la Ciudad de Mexico, y por ello, Boas y Butler consideraron que podría ser la "mejor mediadora... ya que está bastante familiarizada con la situación de la arqueología en México". ${ }^{2}$ Fue desde su ubicación dentro de su casa, en su hogar, desde donde

1 Para una perspectiva diferente de cómo interpretar la imagen pública de la mujer maestra, encontré interesante la lectura queer que Fiol-Matta (2002) hace de Gabriela Mistral.

29 Octubre 1909 Franz Boas a M. Butler (Columbia University -Central Files CU/CF 318/3). 
Zelia Nuttall e Isabel Ramirez...

Zelia fue considerada como una posible mediadora entre dos tradiciones científicas nacionales. Más que sus méritos científicos, en este momento se estaba valorando su carácter diplomático y su capacidad de moverse en ambientes políticos. Franz Boas pensaba que durante el proceso de establecimiento de la Escuela, y dadas las tensas relaciones entre Estados Unidos y México, era necesario contar con alguien que cuidara sus intereses en México y escribió a Butler:

creo que Mrs. Nuttall podría ser la mejor mediadora. Le escribiré para comentarle sobre esta situación, y ver si ella puede conseguir que el gobierno mexicano elija una persona que colabore con nosotros en la Escuela Nuttall está muy familiarizada con la arqueología de México, y esta tomando una postura muy activa en nuestros esfuerzos. (9 Octubre $1909 \mathrm{CU} / \mathrm{CF} 318 / 2$ )

Butler acordó con Boas y contestó: "creo que ella será capaz de poner al gobierno mexicano en acción". (Id.)

La imagen que los dos antropólogos muestran de Zelia Nuttall es la de una mujer con un acceso privilegiado a las esferas arqueológicas y políticas mexicanas. Les atraía su poder para interactuar con mexicanos, algo que ellos no podían hacer tan fácilmente, probablemente porque serían directamente asociados con intereses expansionistas americanos, pero también quizás porque Zelia como mujer, y viviendo en México, sería vista como una persona neutra, menos peligrosa y sin planes oscuros, ligados a la potencia norte americana. Como mujer, se la consideraba un sujeto inocente.

Aunque parecía que Zelia fuera realmente instrumental en estos momentos de fundación de la EIAEA, durante todo su funcionamiento se mantuvo ali margen. Zelia siguió haciendo investigación de forma independiente, participando en arqueología desde distintas ubicaciones nacionales. Es precisamente esta localización múltiple y autónoma que Zelia Nuttall disfrutó lo que me da pie para reflexionar sobre el papel de 
Apen Ruiz Martinez

las mujeres en este momento de profesionalización, cuando la relación entre instituciones, hogares, familias e investigación se estaba reajustando.

\section{Hogares e instituciones: amateurs y profesionales}

A juzgar por los documentos consultados, aún siendo extranjera (o quizás por serlo) Zelia Nuttall tuvo más facilidades para acceder a círculos políticos e intelectuales de México que Isabel Ramírez Castañeda. Zelia practicó arqueología e hizo de ella su ocupación y pasión cotidianas. Sin embargo no se ganaba la vida con la arqueología; su investigación fue siempre financiada por instituciones o personas (el Museo de Pensilvania o Phoebe Hearst). Aunque Zelia era miembro de algunas de las más prestigiosas organizaciones científicas de México y de Estados Unidos, nunca trabajó para una institución con el fin de obtener un salario. Trabajó la mayor parte de su vida en su casa y en las bibliotecas y archivos. Tomó la decisión de convertir su casa en un espacio para practicar arqueología, y según las cartas que escribió tanto a amigos como a sus mentores, estuvo siempre contenta y tranquila en casa. En su correspondencia, no escondía su satisfacción cada vez que se trasladaba a un nuevo lugar y era capaz de hacer un hogar, construir un lugar donde poder establecerse y escribir. Por ejemplo, en 1903, Zelia escribió una carta a la Sra. Phoebe Hearst desde la Ciudad de México donde recién había decidido instalarse. Al igual que otras cartas, el tema a tratar era financiero. La Sra. Hearst había pagado algunos de sus viajes a archivos y bibliotecas; pero en este caso, el motivo de la carta no era conseguir dinero para una nueva investigación, sino compartir con su amiga y mecenas sus planes y decisiones de residencia. Zelia se estaba instalando en la ciudad de México y le agradecía a Phoebe Hearst por la ayuda económica que había recibido de ella "que me ha permitido disminuir la ansiedad que me invadía y que por tanto me permitirá disfrutar, desempacar 
Zelia Nuttall e Isabel Ramirez...

todas mis cosas y asentarme en la primera verdadera casa que nunca he tenido". 3

En ese momento Zelia tenía 43 años y era ya una reconocida investigadora. Había participado en varios congresos internacionales y parte del material que había hallado en los archivos se había exhibido en dos ferias internacionales, la de Madrid en 1892 y la de Chicago en 1893. Sin lugar a duda, era una mujer con una dimensión internacional. En un momento en que la arqueología era sobre todo una práctica privada, no siempre vinculada a instituciones, la organización de un lugar de trabajo en casa era un aspecto primordial en la vida y la carrera de los arqueólogos. A diferencia de los hombres arqueólogos en esos momentos, para Zelia Nuttall es obvio que la búsqueda de un lugar donde poder armonizar el trabajo y la familia era una de las cuestiones centrales de su vida.

Cuando Zelia Nuttall se estableció en Coyoacán ya se había divorciado y estaba haciendo una vez más lo que ya había hecho en otros momentos de su vida en distintos países: reconstruyendo un hogar para ella y su hija Nadine. Zelia compartía cada uno de estos movimientos y relocalizaciones con su mentor. Por ejemplo, a fines de la década de los 1890s escribió una carta a Frederic Putnam desde Lausane (Suiza) diciendo:

me he asentado aquí durante el verano, y he puesto a Nadine en una escuela cercana. Ahora voy a retomar mis estudios y espero realizar un buen trabajo este invierno, lo cual es una delicia para mí (...) actualmente me encuentro en una situación ideal, en un hotel casi vacío, fuera de la ciudad, en la orilla del lago de Ginebra. Estoy disfrutando de una perfecta reclusión y quietud. ${ }^{4}$

324 Enero 1903, Phoebe Hearst Papers, Bancroft Library (PHAH).

41 Noviembre 1895. Zelia Nuttal a Frederic Putnam, Caja 2, Carpeta 1. Zelia Nuttall Papers, Peabody Museum (ZNP/PB). 
Aunque durante toda su vida fue claramente nómada, cada vez que se establecía en un nuevo lugar, Zelia expresaba cierta ansiedad por la voluntad de sentirse conectada emocionalmente a la casa y sus alrededores.

Para Zelia, la posibilidad de trabajar solidamente parecía totalmente ligada al bienestar logrado en su espacio inmediato. En un momento determinado de su vida, pensó que México satisfacía sus deseos de tener un hogar y trabajar cerca del lugar donde se encontraban sus intereses profesionales. Y de esta manera Nuttall compartió con Boas su decisión de establecerse en la ciudad de México porque

me he dado cuenta de que si en los próximos años tengo que pasar una parte de cada año aquí, tengo que tener mis libros a mano, y un lugar donde retirarme para trabajar el material. Teniendo en cuenta todo esto, he llegado a la conclusión de que la mejor cosa que puedo hacer es establecer mi cuartel general en uno de los suburbios de la ciudad de México, donde puedo contar con alimentos, una tranquilidad perfecta y maravillosa, un gran jardín y una casa espaciosa pagando un alquiler muy bajo comparándolo con California. Parece que será fácil traer mis muebles y mis libros, y podré trabajar bien. Desde aquí puedo ir fácilmente a California y al este de Estados Unidos. El clima me favorece mucho. Creo que el plan de establecerme aquí, en la tierra de mis investigaciones, es muy sensata desde todos los puntos de vista. La idea de establecerme ha resultado de una larga deliberación y reflexión y Nadine está encantada con eso, lo cual hace las cosas mucho más fáciles para mí. (27 Mayo 1902 Caja 2, Carpeta 4 [ZNP/PB])

En esta carta, Zelia Nuttall establece un estrecho vínculo entre su espacio privado (Casa Alvarado, su casa de Coyoacán) y el espacio de sus investigaciones (México). El clima le sentaba bien, su hija estaba contenta, y ella podía estar en la tierra de sus investigaciones. Tanto su entorno doméstico como el espacio 
Zelia Nuttall e Isabel Ramirez...

nacional mexicano formaban el terreno arqueológico entendido como espacio de producción científica.

Su casa en México era también un lugar donde intelectuales y científicos se reunían y discutían. A menudo recibía visitantes de fuera de México, era una anfitriona en Casa Alvarado que se tornaba como una especie de salón o parlor "donde invitaba a jóvenes investigadores que se quedaban durante largos períodos, y a quienes ayudaba con sus estudios de arqueología mexicana y de historia colonial". (Chiñas, 1988:271) Desde el interior de su casa estaba conectada con el exterior, podía acercarse al mundo científico y participar en cuestiones arqueológicas tanto nacionales como internacionales.

La relación de Isabel Ramírez con las instituciones y con el espacio doméstico es diferente a la de Zelia Nuttall. Ella precisaba apoyo institucional, y tuvo que vincularse al Museo Nacional porque necesitaba un salario para sobrevivir. Además sabemos que no fue una protegida de la burocracia arqueológica en México. George Engerrand director de la Escuela Internacional en 1913, explicó a Franz Boas que Isabel Ramírez no estaba siendo bien tratada por la administración mexicana: "Le han quitado absolutamente todos los empleos y tiene que pasar la vida en el ministerio para ver de sacar algo. Le tengo mucha compasión porque ha sufrido muchas injusticias". ${ }^{5}$

En esos momentos Engerrand consideraba que la escuela se podría profesionalizar y transformar en un lugar alternativo al Museo Nacional, por eso comentó con Boas la posibilidad de contratar a Isabel Ramírez:

estamos inclinados a solicitar del ministro que se le conceda una pensión con el objeto de que se dedique únicamente a folklore dejando sus empleos y en este caso ella podría ser un elemento permanente de la escuela, como una especie de Secretario. (17 Junio 1913. Carpeta 1, [FBP/APS])

517 Julio 1913. Franz Boas Papers, American Philosophical Society. Carpeta 1, (FBP/APS). 
Pero Isabel no tuvo nunca esa posición, y aunque en 1913 fue elegida para realizar la Carta Arqueológica de México, y se le iba a pagar un salario de $\$ 1.825$ pesos por ello, sabemos que nunca hizo ese trabajo. ${ }^{6}$ Es más, Metchild Rutsch nos explica que a fines de la década de 1910 Isabel Ramírez fue expulsada del Museo Nacional, probablemente por su colaboración profesional con el arqueólogo alemán Eduard Seler, que en esos momentos de intenso patriotismo, no era bien recibido dentro de la comunidad científica mexicana, y que Isabel solo regresó al Museo en 1930 esta vez para trabajar como portera. (Rutsch, 2000)

\section{Amateur por obligación}

Las diferencias entre Isabel y Zelia podrían ser vistas como idiosincrásicas, fruto de sus personalidades o caracteres particulares, pero sus contrastes tuvieron que ver con el contexto social, cultural y político donde las dos mujeres se socializaron (México y Estados Unidos-Europa) con su nacionalidad y su estatus social. A pesar de las diferencias que he señalado, observo similitudes o paralelismo que tienen que ver con el momento de profesionalización y las dificultades que tuvieron las mujeres para lograr entrar de pleno y públicamente en un espacio que especialmente en México, era claramente masculino. Este período de profesionalización de la arqueología y la antropología coincide con la entrada de mujeres en la disciplina que significó también la negociación acerca el espacio de producción científica, el sistema de financiamiento y la forma de escribir. Fue un período en que, como señala Donna Haraway

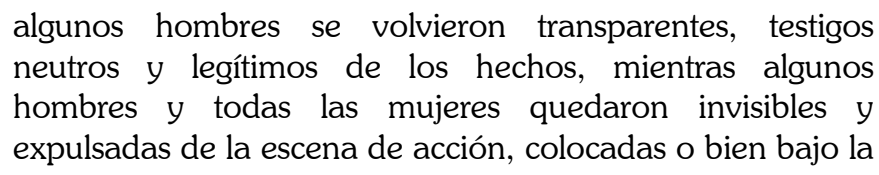

626 Julio 1913. Archivo General de la Nación, Instrucción Pública y Bellas Artes, (AGN/IPBA), Vol. 113,exp.28. 
Zelia Nuttall e Isabel Ramirez...

tarima o completamente fuera de la escena. (Haraway, 1996:433)

En este sentido, aún participando de forma muy diferente tanto Isabel como Zelia fueron sacadas del centro de la acción científica.

Isabel era una profesional, mientras que Zelia se acerca más a la categoría de amateur. Aunque estas categorías pueden ser problemáticas y un poco simplistas, nos sirven como punto de partida para entender la ambigua localización de las mujeres en los primeros momentos de profesionalización. Marilyn Ogilvie, de forma similar a Donna Haraway, argumenta que:

los amateurs fueron poco a poco restringiéndose a ciertas actividades específicas. Gradualmente, el estatus de profesional fue negado a varios grupos de personas por varias razones. Pero desde luego, la oportunidad de hacerse profesional fue casi totalmente cerrada a un grupo importante de personas: las mujeres. (Ogilvie, 2000:67)

Ogilvie concluye que para las mujeres la manera de participar en la ciencia fue como amateurs. La autora llama a estas mujeres "amateurs por obligación", porque hubieran sido profesionales si la ocasión se les hubiera presentado. Estas mujeres, entre las que había ornitólogas, astrónomas, botánicas, geólogas y con seguridad antropólogas y arqueólogas, utilizaron sus capacidades científicas y su trabajo para promover la utilidad de la ciencia amateur. Entre ellas se protegían, se ayudaban económicamente y de esta forma aunque por un lado se mantuvieran en la periferia, a nivel de las prácticas y los resultados, hacían lo mismo que los científicos profesionales.

El concepto de amateur obligatoria que propone Ogilvie, es útil para entender la participación de Zelia Nuttal en arqueología pero no nos ayuda a entender a Isabel Ramírez. Ella no trabajó en casa sino en el Museo Nacional, de donde recibía un salario. Tampoco se benefició de una red de solidaridad femenina que le 
permitiera financiar su trabajo como folklorista o arqueóloga. Las experiencias de estas dos mujeres ponen de relieve como la cuestión de la clase social y la nacionalidad influyó en su práctica científica. Para Zelia Nuttall ser una amateur fue una opción personal y una elección profesional. No requería de un salario y además tuvo ventajas de esta condición, viajando y asentándose en varios lugares según lo requería su investigación.

Zelia Nuttall fue una entusiasta arqueóloga, para ella la arqueología fue más una vocación que una forma de ganarse el sustento. Formó parte de organizaciones científicas tanto en Estados Unidos como en México, hizo trabajo de campo, publicó en revistas científicas, y asistió a conferencias y congresos internacionales. Es decir, contaba con todas las características de una profesional excepto un trabajo remunerado.

Isabel Ramírez sin embargo, se insertó en la arqueología poco a poco, estudiando y vinculándose como asistente a proyectos científicos del Museo, pero no contó con las mismas oportunidades que Zelia Nuttall. Con seguridad, no tuvo acceso a las redes de financiamiento de las que Zelia formaba parte, no contaba con una mecenas que le pagara las cuentas y la investigación, y sin saber inglés o francés era difícil acceder a ámbitos internacionales científicos. De todas formas, como arqueóloga y folklorista, Isabel hizo exactamente lo que cualquier otro científico hacía, aún así, sigue siendo recordada vagamente como una mujer que recogía piezas de cerámica.

\section{La chica que recogía cerámica}

En 1943 Alfred Kroeber estaba recopilando información para escribir un artículo biográfico sobre Franz Boas, y se comunicó con el antropólogo Alden Mason preguntándole varios datos sobre el trabajo y la presencia de Boas en México. Mason había sido un becario de la Escuela Internacional mientras Franz Boas daba clases allí, y le contestó a Kroeber enfatizando el crucial papel de Boas como estimulador de la investigación arqueológica 
Zelia Nuttall e Isabel Ramirez...

y antropológica en México. Recreando los momentos de convivencia en la institución, Alden Mason también escribió sobre las otras personas que trabajaban allí. Entre estas personas, Mason recordaba que "había una chica que o bien recogía cerámica para Franz Boas en Culhuacan o analizaba su cerámica. No recuerdo su nombre, pero creo que publicó sobre este material". ${ }^{7}$ La "chica que recogía cerámica" era Isabel Ramírez Castañeda, una mujer cuya contribución a la Escuela Internacional y en general a la arqueología mexicana, no fue apreciada por sus colegas del momento y tampoco posteriormente.

Probablemente Isabel Ramírez ha sido recordada como una especialista en cerámica, porque esa ha sido y sigue siendo la imagen del trabajo de la mujer en la arqueología. Esta imagen coincide con una división sexual del trabajo que aún se da en la práctica arqueológica en el presente: las mujeres estudian cerámica y los hombres analizan instrumentos líticos, las mujeres se quedan en el laboratorio mientras los hombres salen al campo. (Gero, 1996:251-279) Imaginar a las mujeres con un pico excavando el subsuelo para extraer restos del pasado no ha sido fácil, aunque han existido arqueólogas que lo han hecho. (Picazo, 1988; Ruiz, 2003) La visión de Isabel como una mujer que estudiaba exclusivamente la cerámica, no coincide con la información archivística sobre la Escuela, donde se dice que llevó a cabo diversos tipos de actividades en las diferentes subdisciplinas de la antropología.

En cierta manera la vinculación de Isabel a la Escuela está íntimamente ligada al proyecto científico-antropológico de Franz Boas que le impulsó a salir fuera de las fronteras de Estados Unidos y fundar una escuela profesional en México para seguir investigando cuestiones de migración, contacto e interrelaciones de poblaciones. (Godoy, 1977; Liss, 1995) Con el establecimiento de la EIAEA en México, Boas podía continuar con su interés en

724 Marzo 1943. Alden Mason Papers, American Philosophical Society, (AMP/ APS). 
rastrear la relación entre rasgos indígenas e Hispanos en el folklore y la etnología mexicana; una tarea que posteriormente en los años 1930s continuó la antropóloga norteamericana Elsie Clews Parsons y culminó en la monografía sobre Mitla en Oaxaca. (Parsons, 1936; Deacon, 1997)

En su momento, Franz Boas consideraba a Isabel Ramírez una persona ideal para llevar cabo en México su proyecto científico. Así, bajo el amparo de la Escuela, Isabel Ramírez estuvo encargada de recopilar "cuentecitos e historietas indias" en el pueblo de Milpa Alta, un poblado indígena muy próximo a la ciudad de México. Isabel era hispanohablante, dominaba el Náhuatl que se hablaba entre las comunidades indígenas del centro de México, y por lo tanto recopilaba directamente las historias y mitos indígenas para transcribirlas y luego traducirlas al español. A diferencia de Alden Mason, que estaba también haciendo investigación arqueológica en Jalisco bajo la dirección de Franz Boas, Isabel Ramírez no necesitaba un traductor en el trabajo de campo. Fue quizás su proximidad y familiaridad con lo nativo que atrajo a Franz Boas.

En este sentido, Isabel podría ser la contraparte mexicana de otros estudiantes de Franz Boas, especialmente mujeres, que estaban siendo formadas como antropólogas en Estados Unidos para realizar trabajo etnográfico en lugares primitivos. (Visweswaran, 1998; Deacon,1997) A pesar de la estima y aprecio científico que Boas mostraba por Isabel, otros colegas en la Escuela Internacional afirmaron frecuentemente que era una persona difícil, con un carácter especial. En la correspondencia de la escuela son frecuentes también los comentarios peyorativos sobre su prosa y la falta de rigor científico.

Isabel Ramírez podría haber sido una arqueóloga altamente reconocida en México y no tan solo una anónima chica que "coleccionaba cerámicas antiguas." Como ya hemos visto, ella hizo otras cosas además de estudiar cerámica, pero durante su carrera tuvo que competir con Manuel Gamio, otro joven antropólogo mexicano que ha sido posteriormente recordado 
Zelia Nuttall e Isabel Ramirez...

como el padre de la antropología mexicana y el pionero del método estratigráfico en las Américas. (Adams, 1960; Browman y Givens, 1998) Aunque ambos jóvenes formaron parte de la misma comunidad arqueológica, y mantuvieron contactos con investigadores extranjeros, Manuel Gamio se convirtió en un interlocutor entre tradiciones científicas (De La Peña, 1996; Delpar, 1992; Deacon, 1997) mientras que Isabel Ramírez se mantuvo a la sombra o en un espacio secundario. De todas formas, más que ver a Isabel Ramírez como una mujer que buscó el aislamiento y la marginalidad, creo que lo poco que conocemos de ella nos pone de manifiesto una actitud voluntariamente ambigua hacia la presencia de arqueólogos extranjeros en su país, y un escepticismo por la falta de responsabilidad de ciertos miembros de la Escuela. En 1914 cuando la Escuela suspendió sus actividades después de la entrada de tropas norte americanas en Veracruz, Isabel escribió una carta a Franz Boas diciendo que Alfred Tozzer, el director en aquellos momentos, se había escapado de México abandonando todo el material de la escuela y dejando la situación en un caos total. (9 Mayo 1914. FBPP)

Así como Isabel mostró su enfado por la irresponsabilidad de Tozzer en los momentos finales de la escuela, la opinión que circulaba en la escuela subrayaba su apatía y desidia en relación a la investigación. Durante el período en que George Engerrand fue director de la Escuela se quejó varias veces sobre ella. En su correspondencia con Franz Boas, Engerrand manifestaba que el especial carácter de Isabel y, sobretodo su vanidad eran un gran problema que interfería con su trabajo como arqueóloga. Engerrand la encontraba

un esprit faux, que comprende muchas veces las cosas al revés. Además es peligrosa porque desgarra a todos. En mi concepto es casi completamente nula y lo que complica las cosas, es de una vanidad que no tiene limites. (5 Noviembre 1912. FBPP) 
Engerrand revelaba al mismo tiempo una actitud paternalista hacia Isabel, esperando que bajo su tutela o influencia, cambiara su forma de ser. De esta forma expresó a Boas "necesitaré suma prudencia con ella pero quiero conquistarla con mucha bondad y procurando canalizar su vanidad hacia las satisfacciones que pudiera proporcionarle la producción intelectual". (Id.)

Boas no compartía con Engerrand esta opinión sobre Isabel y fue claramente honesto con él en relación a este tema "no tengo las objeciones personales contra ella que usted parece tener. Más bien la encuentro siempre dispuesta y bastante confiable cuando se le da un encargo para trabajar". (18 Noviembre 1912. FBPP) Es más, Boas consideraba a Isabel la persona idónea para realizar estudios de folklore, aunque es cierto que comentó los problemas que ella tenía con escribir.

Así, le contesto a Engerrand:

me parece que entre todas las personas que contamos para realizar este tipo de estudios, Isabel es la mejor preparada, si conseguimos que supere sus indecisiones y vacilaciones para escribir. (2 Abril 1913. FBPP)

Por otro lado, las críticas que Isabel recibió nunca se centraron en su capacidad científica sino en su carácter y en su manera de escribir. Como explico a continuación, la cuestión de escribir fue tanto para Isabel como para Zelia un tema que acompañó sus vidas como antropólogas.

\section{Escribir desde distintas ubicaciones}

Preocupaciones sobre la escritura se filtran en la vida de las dos mujeres de las que hablo en este artículo. La forma de escribir de Isabel Ramírez no era valorada por sus colegas y mentores, quienes o bien criticaban su ortografía o querían transformar su escritura en una narrativa más científica y menos literaria. Su estilo era percibido como un problema, algo que debía ser transformado, y al mismo tiempo era una excusa para denigrarla 
Zelia Nuttall e Isabel Ramirez...

como científica. Engerrand, por ejemplo dudó sobre las aptitudes de Isabel para escribir, y confundió su capacidad de investigar con su forma de escribir. En una carta a Boas, expresó "la encuentro muy dispuesta, pero no puedo menos que hacerle observar que su español no es muy bueno y que hace falta de ortografía". (21 Abril 1921. FBPP)

No obstante, tras leer los pocos trabajos que se conservan de Isabel Ramírez no me parece que fuera incapaz de escribir correctamente en español. Lo que parece ocurrir es que Engerrand minuciosamente fabricó una imagen de Isabel como alguien incapaz de escribir, una característica que parecería que transformaba a Isabel en una científica inepta. En una carta a Boas, Engerrand expresó esta preocupación

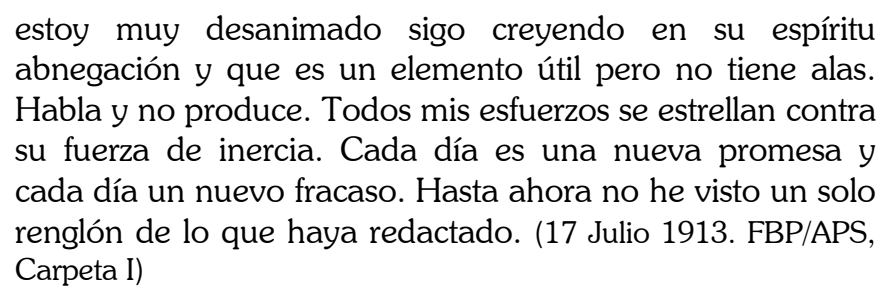
abnegación y que es un elemento útil pero no tiene alas. Habla y no produce. Todos mis esfuerzos se estrellan contra su fuerza de inercia. Cada día es una nueva promesa y cada día un nuevo fracaso. Hasta ahora no he visto un solo renglón de lo que haya redactado. (17 Julio 1913. FBP/APS, Carpeta I)

De esta forma, Isabel fue retratada como una mujer llena de posibilidades pero incapaz de salir adelante.

Las infundadas acusaciones que hizo Engerrand sobre la ortografía de Isabel Ramírez no son mínimas anécdotas sino que están relacionadas con dos cuestiones más amplias sobre la antropología. (Minh-Ha, 1989; Abu-Lughod, 1991; Visweswaran, 1994) Por un lado, Isabel trabajaba bajo la supervisión de Franz Boas en un momento en el que la antropología y la arqueología se estaban estableciendo como ciencia con unos métodos y unas reglas de escritura específicas. Por otro lado, como maestra, Isabel buscaba un estilo para comunicar su conocimiento antropológico a los alumnos. Y era posible que las exigencias metodológicas como antropóloga entraran en contradicción con las de maestra de escuela. Ella había sido educada para explicar a los niños las 
historias que recogía como folklorista y antropóloga. Por un lado tenía que procesar el conocimiento antropológico para ser entendida en las escuelas, y por otro tenía que lograr un estilo de comunicación que también cumpliera los requisitos de la disciplina científica.

Durante su implicación en la Escuela Internacional en México, Franz Boas fue insistente en establecer las normas que debían seguirse para recoger y transcribir historias y narrativas indígenas. La prioridad, decía Boas, es

conseguir que la mayor parte de la información sea dictada por los que conocen los cuentos, y sobretodo habría que inducir a que ellos mismos escribieran lo que saben. Este método es muy productivo y se consigue que el material nos llegue de forma inadulterada. (2 Abril 1913. FBPP)

Boas opinaba que el estilo de Isabel era demasiado ficticio y que necesitaba mantenerse más próxima al texto real, y así comentó:

creo que la Srta. Castañeda piensa que este tipo de material debe ser transformado en un texto literario; pero creo que eso es erróneo. De hecho, el material debería registrarse de la forma más exacta posible, y los únicos cambios que se admiten serían aquellos que mejoraran la ambigüedad inherente en la expresión. (2 Abril 1913. FBPP)

Esta fidelidad al texto, la necesidad de obtener una historia verdadera y poco ambigua, estaba en conflicto con la idea que Isabel tenía de recoger material para poder contar historias a los niños en las escuelas, lo que ella denominaba cuentecitos $e$ historietas.

Como maestra, Isabel contaba con estrategias para comunicarse con los alumnos, y su trabajo de campo era una forma de conseguir material que luego podía transformar en historias para usar con sus estudiantes. Si lo vemos en este 
Zelia Nuttall e Isabel Ramirez...

sentido, Isabel era una nativa al igual que una intérprete de la cultura que estudiaba, y el lenguaje y la escritura jugaban un papel muy importante en esta identidad dual. Su escritura le hacía parecer más una contadora de cuentos que una antropóloga distante. Este posicionamiento entraba en contradicción con lo que Boas consideraba principios de correcta investigación, en la cual la ubicación del antropólogo no debía de ser de "total inmersión sino de lejanía, porque solo esta perspectiva te da legitimidad para obtener 'verdades'." (Liss, 1995:129)

Isabel estaba quizás menos preocupada en buscar verdades antropológicas que en popularizar su conocimiento del folklore indígena $y$ transformarlo en forma literaria. Sus escritos arqueológicos fueron vistos como faltos de autoridad científica, cuando en realidad Isabel estaba siendo honesta y humilde con la manera en que se interpretan los datos arqueológicos. Por ejemplo tras un trabajo de campo en Tlanepantla, empezó un informe arqueológico afirmando "muy penoso es para mí hacer estos ligerísimos apuntes, pero tengo que llenar una obligación y debo pretender descifrar lo que probablemente pudieron significar los monumentos allí existentes". (1908, manuscrito inédito) El tono de estas palabras denota una modestia científica que fue interpretada como una falta de seguridad y confianza personal y Engerrand criticó afirmando que Isabel era una mujer con falta de iniciativa, una mujer que "no tiene alas". Sin embargo, si tenemos en cuenta a Isabel como folklorista y como maestra, lo que se deduce es que consiguió escribir desde posiciones diferentes para lograr una escritura que fusionara audiencias y expectativas diferentes. Algo semejante se observa en Zelia Nuttall, que utilizaba diferentes estrategias de escritura según su posicionamiento como científica y como mujer y según la audiencia que iba a leerla.

Zelia Nuttall estuvo siempre interesada en resolver la cuestión del origen de la civilización mexicana, y aunque ese interrogante arqueológico la acompañó durante toda su vida, tenía muy claro que la naturaleza de la investigación arqueológica no siempre la llevaba a soluciones absolutas y definitivas. En sus 
escritos acerca de la civilización antigua mexicana Zelia dejaba entrever su postura reflexiva hacia la ciencia:

cuanto más exploro sus desconocidos caminos y descubro las múltiples y contradictorias características, menos capaz me veo de formular conclusiones sobre este tema. Frecuentemente el descubrimiento de material inédito, o los resultados inesperados que surgen de una nueva línea de investigación, obligan a los estudiosos a alterar o reajustar sus visiones o hipótesis de trabajo. (Nuttall, 1906:134)

Zelia era además explícita en cómo su entorno emocional afectaba su capacidad de escribir. Desde los inícios de su carrera, expresaba una necesidad de tener un espacio físico, emocional y simbólico que le permitiera trabajar con tranquilidad. Compartía con Frederic Putnam la incapacidad que sentía para escribir, y asociaba esa incapacidad y lentitud en acabar artículos a la inconformidad con su espacio familiar, en particular su matrimonio. En palabras de Zelia, el retraso en producir artículos se debía a una "depresión tanto de espíritu como de salud a causa de un montón de asuntos dolorosos relacionados con mi matrimonio, y no veo como puedo obtener alguna protección para mí y para mi hija".

Aunque los detalles de su vida matrimonial y las circunstancias de su separación no son explícitas en su correspondencia, es evidente que las dificultades de su matrimonio y de su proceso de separación afectaron su trabajo y la forzaron a "no aceptar ninguna tarea más, a no hacer compromisos ni planes hasta que esté todo en orden de nuevo".

En la última parte de este artículo contrasto la falta de confianza que Zelia expresa sobre su escritura con la forma de escribir que usó en una confrontación pública que tuvo en 1910

84 Marzo 1888. Caja 2, Carpeta I. Zelia Nuttall Papers - Peabody Museum (ZN/PM).

9 Zelia Nuttall a Frederic Putnam. 22 Julio 1888. Caja 2 Carpeta I (ZN/PM). 
Zelia Nuttall e Isabel Ramirez...

con Leopoldo Batres (Inspector de Monumentos en México) después de que ella participara en trabajo de campo en La Isla de los Sacrificios (Veracruz, México). En este incidente, Zelia decidió que el lugar apropiado para ella como científica era un espacio mucho más público que los que había ocupado anteriormente en su vida. Hasta ese momento, Zelia había realizado la mayor parte de sus estudios en bibliotecas y archivos, y fue precisamente cuando salió al exterior para hacer trabajo de campo, cuando su voz fue abiertamente cuestionada. Zelia salió fuera de un espacio científico que estaba designado para las mujeres (la biblioteca) y se involucró directamente en un espacio público y masculino: el suelo nacional. Zelia no se quedó silenciosa frente a los ataques de Batres, al contrario, publicó tres breves pero contundentes artículos en un periódico de la ciudad de México. En esta ocasión dejó atrás los miedos a escribir que había expresado en otros momentos de su vida y convirtió su voz científica y de mujer en una voz pública.

\section{Una señora no puede trabajar fuera de la biblioteca}

En medio del conflicto, Zelia escribió una carta a su viejo amigo y profesor Franz Boas explicando con gran descontento la decisión de renunciar a su título de

Profesora Honoraria del Museo Nacional de México como protesta por el tratamiento que he recibido a partir de mi descubrimiento y mi propuesta de investigar las ruinas de la Isla de los Sacrificios (...) Mi trabajo fue entorpecido en todos los sentidos, y las condiciones que se me ofrecieron para llevar a cabo mi trabajo eran tales que ningún arqueólogo que se haga respetar las hubiera aceptado. Mientras tanto yo me retiro a mi "vida privada" y a trabajar en cosas que no requieren la autorización del Ministerio. (6 Abril, 1910. FBPP) 
Esta reclusión a la "vida privada" de la que escribe Zelia, no significó un abandono de la arqueología. Zelia estaba hablando de una forma más simbólica que real: continuó investigando y publicando durante el resto de su vida, pero ciertamente en ese momento decidió que como arqueóloga iba a permanecer dentro y no fuera. Tras los acontecimientos de 1910 Zelia dió por finalizada su breve estancia en el campo, en el terreno donde se hallaban enterrados los restos arqueológicos. Con la excepción de una excavación realizada en el jardín de su casa en Coyoacán, el espacio arqueológico de Nuttall volvió a ser la biblioteca y su casa, leyendo libros y manuscritos, algunas veces visitando museos y observando los objetos que otras personas habían excavado, pero su práctica arqueológica nunca más se llevó a cabo en un espacio exterior, visible al público. Veamos ahora lo que ocurrió en 1910 en la Isla de los Sacrificios.

Zelia visitó la isla por primera vez en 1909, acompañada por su amiga Mrs. Hamilton y observó restos de cerámica desparramados por la superficie. Tras esa visita, preparó un informe preliminar y lo presentó ante la administración mexicana para pedir un permiso de excavación. Aunque el gobierno respondió comprometiéndose a darle fondos para cubrir gastos, Zelia, no se comportó como una profesional y ofreció sus servicios y su tiempo de forma gratuita. Después de la excavación, publicó un artículo donde propuso una "hipótesis de trabajo": la isla podía haber sido Aztlán, el mítico hogar de los Aztecas, un lugar con resonancia en la imaginación nacionalista mexicana. Sin duda, la hipótesis de Nuttall era provocadora porque se refería a la delimitación de un punto geográfico e histórico de origen nacional. Y era una hipótesis provocativa porque estaba hecha con voz de mujer.

Zelia reclamó una autoridad científica y responsabilidad de su descubrimiento en la Isla de los Sacrificios y lo hizo desde su posición como mujer y extranjera en México. Mary Ann Levine ha escrito sobre la confrontación entre Nuttall y Batres planteando que es posible que el hecho de que Zelia fuera una mujer que se 
Zelia Nuttall e Isabel Ramirez...

movía en ámbitos de gran importancia científica provocara sentimiento negativos entre sus colegas hombres. (Levine, 1999:40) Esta autora, sin embargo no presta suficiente atención al hecho de que el incidente entre Nuttall y Batres tuvo lugar en México donde Zelia era una mujer extranjera, y que desde esa posición fue muy atrevida al investigar un tema que tenía que ver con los orígenes de la nación y en el cual, la investigación del pasado estaba centralizada en manos de un inspector de monumentos. Además era un cuerpo femenino el que estaba en la isla sacando a la luz unos restos materiales que podrían alimentar discursos nacionalistas.

Más que accidental, el conflicto entre Batres y Nuttall tiene sentido dentro de un contexto más general del nacionalismo mexicano y la búsqueda de un lugar de origen para la nación. Aunque Zelia era una reconocida científica, en el caso de la Isla de los Sacrificios su legitimidad y autoridad científica no fue tomada en cuenta. Batres, como máximo representante de la arqueología mexicana no aceptó que el origen arqueológico de la nación fuera situado en la Isla de los Sacrificios, en el estado de Veracruz. Aunque nunca ofreció una interpretación alternativa sobre los restos materiales de la isla, Batres tenía claro que el origen geográfico y cultural de la nación debía estar situado en el centro de la nación moderna, es decir, cerca de la Ciudad de México. Y con esa lógica centralista, cuando se expuso la cerámica de la Isla de los Sacrificios en el Museo Nacional, la etiquetó como si procediera de Teotihuacan, ciudad antigua ubicada cerca de la capital. Zelia se enfureció y denunció a Batres acusándole de falsificador. Batres respondió a las acusaciones con un panfleto en el cual no rebatía científicamente a Nuttall pero la atacó personalmente. (Batres, 1910)

Batres argumentó que no había escrito ese artículo para contradecir "a la señora Zelia Nuttall de Pinard, pues la mujer ha sido siempre para mí el objeto de veneración y respeto" (Batres, 1910:3), sino para defenderse de los daños que ella le había causado al denunciarle de falsificador. Al mismo tiempo que 
Batres veneraba a la señora Nuttall por ser una mujer, cuestionaba su voz científica:

¿quién es la Sra. Nuttall de Pinard para juzgar de si está bien o está mal hecha la clasificación que he llevado a cabo en el Museo Nacional? ¿Qué autoridad tiene? Qué acaso una simple aficionada sin educación científica ni artística ¿puede juzgar de asuntos científicos de alta jerarquía? (Id.: 4)

Zelia respondió a Batres escribiendo cuatro artículos que fueron publicados en la revista Mexican Herald. ${ }^{10}$ En esos artículos intentó despersonalizar la controversia y darle un contenido más científico. Zelia se defendió de las críticas que Batres había hecho acerca de su falta de competencia científica y propuso que iba a

publicar pruebas apoyando mis argumentos en las hospitalarias columnas del Mexican Herald. Mis artículos aparecerán sistemáticamente cada semana y tendrán la forma de tres parágrafos. El parágrafo I siempre contenderá una negación, refutación o discusión analítica de una o mas de las afirmaciones falsas que usted ha hecho sobre mí. El parágrafo II siempre contendrá ampliaciones o substanciaciones de una de las afirmaciones que usted hizo sobre mí. El parágrafo III estará dedicado a misceláneas o cuestiones que surjan de forma inesperada. (Nuttall, 10 Diciembre 1910)

Batres respondió siempre llevando la disputa a un terreno personal, descalificándola como científica. Describió a Zelia como una mujer histérica porque había sido incapaz de mantener una conversación racional y calmada con él sobre el tema de las cerámicas de la Isla de los Sacrificios. Según Batres, la arqueóloga ${ }^{10}$ Nuttall, 10 Diciembre 1910, 17 Diciembre 1910, 15 Enero 1911, 16 Enero
1911. 
Zelia Nuttall e Isabel Ramirez...

tenía "lágrimas en los ojos, y la boca presa de una convulsión histérica". (Batres, 1910:9) Zelia respondió fuertemente diciendo

es posible que haya reaccionado un poco más fuerte de lo normal. Pero Señor Batres, le aseguro que no estaba en un estado de histeria casi rozando la demencia como usted dice. Desde luego, una persona de mi edad no puede permitirse el lujo de menospreciar el famoso consejo de Telleyrand "nunca ladres si no sabes que puedes morder". (Nuttall, 10 Diciembre 1910)

Es más, Zelia parecía consciente de que Batres estaba haciendo un comentario sexista y claramente le dijo

las condiciones de histerismo no están limitadas al sexo que usted tan caballerosamente afirma que respeta, pero que está claro que es un respeto que solo tienen aquellas mujeres que aceptan sus clasificaciones y etiquetas de museos con reverencia y fé indiscutible. (Id.)

Los hallazgos en la Isla de los Sacrificios no fueron decisivos para la arqueología mexicana. La controversia entre Batres y Nuttall nunca se resolvió científicamente. Sin embargo este incidente nos habla sobre la dinámica de género en la producción de conocimiento científico y también sobre las dificultades de que una mujer pudiera hablar sobre nación. La disputa sobre los hallazgos en la Isla de los Sacrificios puede verse como uno de esos momentos en la historia de la arqueología en el cual la voz científica femenina se estaba haciendo pública y enfrentaba resistencias.

\section{Conclusiones: naciones y feminismo en arqueología}

Uno de los temas de interés para las arqueólogas feministas ha sido encontrar y rastrear la vida de las mujeres en la historia de la disciplina. Sin duda, poder documentar algunos episodios de la vida de Isabel Ramírez y Zelia Nuttall es parte de un proyecto que 
nos permitirá reconocer que la práctica de la ciencia no fue un asunto exclusivamente masculino. El trabajo de varias académicas ha confirmado que las mujeres han estado presentes en la ciencia Americana y Europea. Sin embargo necesitamos aún más investigaciones sobre mujeres científicas (no solamente antropólogas) en otras regiones fuera de Estados Unidos y Europa, así como de las relaciones entre científicas de diferentes nacionalidades que consiguieron salir del esquema de las tradiciones nacionales $\mathrm{y}$ formar parte de una comunidad transnacional de mujeres científicas trabajando en proyectos semejantes. (Ver Corrêa, 2003; Henson, 2002)

Considero a Zelia Nuttall e Isabel Ramírez protagonistas centrales al mismo tiempo que personajes marginales de un momento de la historia de la arqueología. Participaron en instituciones y proyectos arqueológicos de gran envergadura pero como mujeres también fueron marginadas. Zelia Nuttall, como otras mujeres científicas del momento se incorporó a la arqueología a su manera y con cierta autonomía. Pero eso no fue posible para Isabel Ramírez. Las distintas experiencias de estas dos mujeres indican que en la práctica de la arqueología, los privilegios sociales y nacionales intervienen en la noción de una identidad femenina científica e universal.

Es decir, aunque como mujeres fueron alejadas de ciertos espacios científicos, Zelia e Isabel tuvieron experiencias únicas porque su nacionalidad y su condición social les marcó de una forma distinta a cada una de ellas. Ambas fueron mujeres únicas y quizás excepcionales para su tiempo, pero sus biografías evocan o apuntan algunos aspectos generales sobre la importancia del género y de la nación en la construcción del conocimiento arqueológico. Al mismo tiempo, sus historias nos recuerdan que la marginalización de los cuerpos femeninos de la práctica científica necesita ser nacional e históricamente contextualizado. Para algunas mujeres, involucrarse en proyectos transnacionales fuera de sus fronteras nacionales y de sus sociedades, era una forma de escapar de discursos nacionalistas con imágenes fijas de mujeres 
Zelia Nuttall e Isabel Ramirez...

en el trabajo de campo. A partir de las experiencias de estas mujeres que en su momento transcendieron las fronteras de lo que se estaba consolidando como antropología americana invito a hacer una reflexión acerca de cómo la antropología y la nación se articulan.

\section{Referencias bibliográficas}

ABU-LUGHOD, Lila. Writing against culture. In: FOX, Richard. (org.) Recapturing Anthropology: Working in the Present. Santa Fe, School of American Research, 1991, pp.137-162.

ADAMS, Richard. Manuel Gamio and Stratigraphic Excavation. American Anthropologist 26 (1), 1960.

American Anthropologist. Special Centennial Issue, vol. 104 (2), Junio 2002.

BABCOCK, Barbara y PAREZO, Nancy. Daughters of the Desert. Women Anthropologists and the Native American Southwest 1880-1980. Alburquerque, University of New Mexico Press, 1988.

BATRES, Leopoldo. La Isla de los Sacrificios. La Señora Zelia Nuttall de Pinard y Leopoldo Batres. México, Tipografía Económica, 1910.

BERNAL, Ignacio. Historia de la Arqueología en México. México DF, Ed. Porrúa, 1992.

BROWMAN, David y GIVENS, Douglas. Stratigraphic Excavation: The First "New Archaeology". American Anthropologist 98 (1), 1998, pp.80-95.

CANO, Gabriela. De la Escuela Nacional de Altos Estudios a la Facultad de Filosofía y Letras, 1910-1929. Un proceso de feminización. Tesis de Doctorado, Historia, UNAM, 2000a.

Género y Construcción cultural de las profesiones en el Porfiriato: magisterio, medicina, juridisprudencia y odontología. Historia y Grafía (14), México DF, Universidad Iberoamericana, 2000b, pp.207-243.

CHIÑAS, Beverly N. Zelia Maria Magdalena Nuttall (1857-1933). In: GACS, Ute; KHAN, Aisha; McINTYRE, Jerry; WEINBERG, Ruth. (orgs.) Women Anthropologists: A bibliographic dictionary. New York, Greenwood Press, 1988. 
Apen Ruiz Martinez

CORRÊA, Mariza. Antropólogas e Antropologia. Belo Horizonte, Editora UFMG, 2003.

DAVIS, Natalie Z. Fiction in the Archives: pardon tales and their tellers in sixteenth-century France. Stanford, Stanford University Press, 1987.

DE LA PEÑA, Guillermo. Nacionales y extranjeros en la historia de la antropología mexicana. In: RUTSCH, Metchild. (org.) La historia de la antropología en México: fuentes y transmisión. México DF, UIA-INIPlaza y Valdés, 1996, pp.41-81.

DEACON, Desley. Elsie Clews Parsons. Inventing Modern Life. Chicago, Chicago University Press, 1997.

DELPAR, Helen. The Enormous Vogue of Things Mexican. Cultural Relations between the United States and Mexico 1920-1935. Tuscaloosa, The University of Alabama Press, 1992.

FIOL-MATTA, Licia. A Queer Mother for the Nation: the State and Gabriela Mistral. Minneapolis, University of Minnesota Press, 2002.

GACS, Ute. Women Anthropologists: selected biographies. Urbana, University of Illinois Press, 1989.

GERO, Joan. Archaeological practice and gendered encounters with field data. In: WRIGHT, Rita. (org.) Gender and Archaeology. Philadelphia, University of Pennsylvania Press, 1996, pp.251-279.

GODOY, Ricardo. Franz Boas and his plans for an International School of American Archaeology and Ethnology in Mexico. Journal of the History of Behavioral Sciences 13, 1977, pp.228-242.

HARAWAY, Donna. Modest Witness: Feminist Diffractions in Science Studies. In: GALISON, Peter. (org.) The Desunity of Science. Boundaries, Contexts, and Power. Stanford, Stanford University Press, 1996.

HENSON, Pamela. Invading Arcadia: Women Scientists in the Field in Latin America 1900-1950. The Americas 58(4), 2002, pp.577-600. [Tradução para o português: Cadernos Pagu (15) - Gênero, ciências, história -, Núcleo de Estudos de Gênero - Pagu/Unicamp, 2000, pp.165-198.]

LAWRENCE, D.H. La Serpiente Emplumada. Barcelona, Montesinos, 2000. 
Zelia Nuttall e Isabel Ramirez...

LEVINE, Mary Ann. Uncovering a Buried Past: Women in Americanist Archaeology before the First World War. In: KEHOE, A. y EMMERICHS, M.B. Assembling the Past Studies in the Professionalization of Archaeology. Alburquerque, University of New Mexico Press, 1999.

LISS, Julia E. Pattems of Strangeness. Franz Boas, Modernism, and the Origins of Anthropology. In: BARKAN, Elazar. (org.) Prehistories of the Future. The Primitivist Project and the Culture of Modernism. Stanford, University of California Press, 1995, pp.114-130.

MARK, Joan. A Stranger in Her Native Land. Alice Fletcher and the American Indian. Lincoln, University of Nebraska Press, 1988.

MINH-HA, Trinh. Women, Native, Other. Bloomington, Indiana University Press, 1989.

NUTTALL, Zelia. Some Unsolved problems in Mexican archaeology. Lancaster, The New era Printing Company, 1906.

Mrs Nuttall Ready to Prove Her Claims Against L. Batres. Mexican Herald, 10 Diciembre, 1910.

. Three Paragraphs by Mrs. Zelia Nuttall in Which She Carrects further Statements. Mexican Herald, 17 Diciembre 1910.

Mrs. Nuttall Continues the Controversy With Leopoldo Batres, the Inspector ofthe Archeological Monuments in the Republic of Mexico. Mexican Herald, 16 Enero, 1911.

Public Voice. Mrs Zelia Nuttall Discusses Archaeological Research in Mexico. Mexican Herald, 15 Enero, 1911.

OGILVIE, Marilyn Bailey. Obligatory amateurs: Annie Maunder (18681947) and British women astronomers at the dawn of professional astronomy. British Journal of the History of Science 33, 2000.

PAREZO, Nancy. Hidden Scholars: women anthropologists and the Native America Southwest. Alburquerque, University of New Mexico Press, 1993.

PARSONS, Elsie Clews. Mitla, Town of the Souls and other Zapotecospeaking Pueblos of Oaxaca. Chicago, The University of Chicago Press, 1936.

PICAZO, Marina. Fieldwork is not the proper preserve of a lady. The First women archaeologists in Crete. In: DIAZ-ANDREU, Margarita. (org.) 
Excavating Women: A History of Women in European Archaeology. Londres, Routledge, 1998.

RUIZ, Apen. Bodies that discover/erased bodies: Eulalia Guzmán and the impossibility of digging up the nation. American Anthropological Meetings, New Orleans, Noviembre 2003.

RUTSCH, Metchild. EI patrimonio arqueológico mexicano y la Intemational School of American Archaeology and Etnology. Ludus Vitalis, VIII (14), México, 2000, pp.131-162.

VAZQUEZ, Luis. Historia y constitución profesional de la Arqueología mexicana (1884-1940). In: CABRERO, M. T. (org.) II Coloquio Pedro Bosch Gimpera. México DF, IIA-UNAM, 1993, pp.36-77.

VISWESWARAN, Kamala. "Wild West" Anthropology and the Disciplining of Gender. In: SILVERBERG, H. (ed.) Gender and American Social Sciences. Princeton, Princeton University Press, 1998, pp.87-123

. Fictions of Feminist Ethnography. Minneapolis, University of Minnesota Press, 1994. 